Article

\title{
Site Selection of Co-Working Spaces under the Influence of Multiple Factors: A Case Study in Hangzhou, China
}

\author{
Weiwu Wang ${ }^{1,2, *}$, Jingyi Liang ${ }^{1}$ and Jie Niu ${ }^{1}$ \\ 1 Institute of Urban and Rural Planning Theories \& Technologies, Zhejiang University, \\ Hangzhou 310058, China; liangjingyi0721@zju.edu.cn (J.L.); niujie1010@zju.edu.cn (J.N.) \\ 2 Center for Balance Architecture, Zhejiang University, Hangzhou 310058, China \\ * Correspondence: weiwuwang@zju.edu.cn
}

check for updates

Citation: Wang, W.; Liang, J.; Niu, J. Site Selection of Co-Working Spaces under the Influence of Multiple Factors: A Case Study in Hangzhou, China. Sustainability 2022, 14, 2676. https://doi.org/10.3390/su14052676 Academic Editor: Pierfrancesco De Paola

Received: 17 January 2022

Accepted: 22 February 2022

Published: 25 February 2022

Publisher's Note: MDPI stays neutral with regard to jurisdictional claims in published maps and institutional affiliations.

Copyright: (c) 2022 by the authors. Licensee MDPI, Basel, Switzerland. This article is an open access article distributed under the terms and conditions of the Creative Commons Attribution (CC BY) license (https:// creativecommons.org/licenses/by/ $4.0 /)$.

\begin{abstract}
Co-working spaces (CWSs) have gradually become a new form of spatial economic activity in large cities in China. This not only innovates the traditional office model, but also helps to realize the efficient utilization of office buildings and the sustainable development of office spaces. Taking Hangzhou as a case study, this paper uses big data analysis technologies including Python and ArcGIS to reveal the distribution characteristics of CWSs. From the perspectives of traffic accessibility, business atmosphere, innovation environment, living convenience, and rental cost, we innovatively constructed an indicator system of factors affecting site selection of CWSs. We then conducted an empirical study to reveal the influence mechanism behind different factors. Our conclusions are as follows: (1) CWSs in Hangzhou generally present a multi-center distribution pattern; (2) based on the different degrees of dependence of the target customer groups on resources such as commerce, capital, and information, the factor that has the most significant impact on the site of CWSs is the regional innovation environment, and its weight is 0.3941 . The order of importance of other influencing factors is the convenience of life (0.3147), business atmosphere (0.1352), and traffic conditions (0.1171). The cost of rent has the most negligible impact on site selection, and its weight is only 0.0195 . We hope that the research can be used to provide a scientific basis for the rational planning and development guidance of CWSs.
\end{abstract}

Keywords: co-working spaces; sharing economy; site selection; distribution characteristics; entropy method; innovation environment; sustainable development

\section{Introduction}

With the development of technologies such as the mobile internet, the internet of things, and big data, the sharing economy, as a new collaborative economy that maximizes value, has gradually replaced the old and closed capital model. Its development has not effectively integrated the market's idle resources, improving the overall utilization of resources, dramatically reducing transaction costs, and fostering new economic forms and consumption concepts, covering areas involving transportation, urban housing, tourism, leisure, and green energy [1-7]. At the same time, the development of the sharing economy and the knowledge-based economy has also significantly changed people's lifestyles and work styles, leading to a continuous increase in the proportion of decentralized, mobile, and independent laborers [8]. In this context, as a new office model that uses shared office space to reduce rental costs and improve space resource utilization, the co-working space (CWS) caters to many small and medium-sized enterprises with its low price, flexible lease period, and intense community atmosphere. With the help of capital, the co-working industry has gradually developed a wave of rapid expansion around the world, and many international enterprises such as WeWork, Regus, and Hub have been born [9]. Major operators integrate vacant office resources on the market through leasing, by leasing out to multiple companies in a subleasing model of "breaking up the whole into parts" after a renovation, while providing a series of diversified value-added services. 
The concept of CWS was first proposed by BradNeuberg in 2005. In this space, users not only share the office environment and facilities but also share some information resources, which naturally produces a cooperative relationship [10]. Specifically, CWS is a common area composed of people sharing the same office space, with workers of different occupations. It provides professional facilities and a social communication place, aiming to promote interpersonal relationships and cooperation within the space [11,12]. CWS is also a new type of workplace characterized by an open-space working-environment between the home office and traditional office, which reflects a living atmosphere, spirit, and lifestyle $[13,14]$. CWS is regarded as an emerging social innovation within the collaborative economy. It provides users with a low-cost office space and an information exchange platform, which helps achieve the sustainable use of office resources. Furthermore, it also plays a crucial role in supporting social and professional interaction and promoting urban innovation and intellectual development [15-17].

Current research of CWSs has mainly concentrated on economic management and space design. In terms of business operation, Capdevila [18] believes that traditional industrial clusters are being replaced by innovative networks composed of networked micro-enterprises, and that CWSs happen to provide the necessary intermediaries and physical platforms for such network activities. Zhang et al. [19] used the business model canvas and found that CWSs advocate community development in the growth strategy. Liang [20] constructed an indicator system for rent influencing factors, proposing that the rent of CWSs is positively correlated with office building facilities, the number of surrounding banks, and regional centrality. In terms of interior space design, Soegoto and Hafandi [21] started with anthropometry and ergonomics, believing that the good design of a CWS is closely related to an increase in its users productivity. Ondia et al. [22] have shown that the barriers and field elements in CWSs have a significant impact on the four working modes of coworking, cooperation, socialization, and learning. Nagarathinam et al. [23] proposed that a CWSs design needs to address users with potentially widely varying thermal comfort preferences. As the design concepts of humanization, intelligence, and environmental protection continue to rise, it also provides new ideas for the development and design of interior furniture in CWSs [24-26].

Location refers to the space of human economic activities, and the development of location theory is closely related to actual economic development. Thunnen's agricultural location theory held that due to the difference in the distance between the land and the urban market, the diverse agricultural costs will have different effects on land rent [27]. Location selection is an economic behavior, and the subjects of location selection make choices under imperfect competition and imperfect information [28]. Weber [29] believes that cost is the basic factor affecting the site selection of industrial enterprises, a factor that is composed of transportation costs and labor costs. Hamilton et al. [30] emphasized how the site selection of enterprises depends on the interaction of organizational management objectives. Some scholars have also pointed out that the main factor affecting the site selection of high-tech enterprises is the regional milieux innovation, while the location choice of manufacturing small and medium enterprises is influenced by a combination of location-specific, personal, and community factors $[28,31]$.

As a new form of spatial economic activity in large cities, the location of CWS can often reflect its commercial preferences. And the distribution characteristics of CWSs have received attention in the literature. Salinger [32] studied the spatial location of CWSs, finding they have prominent cluster distribution characteristics, and most of them are located in urban centers. Mariotti et al. [33] took Milan as an example to explore the distribution characteristics of CWS, as well as their impact on the urban area, and believe that their site model is similar to the service industry in urban areas. Wu et al. [34] studied the geographical distribution pattern of CWSs in Shanghai and found that CWSs are mainly concentrated on the west side of the Huangpu River in the inner ring area. Dianovita and Khoirunurrofik [35] found that the distribution pattern of Jakarta's CWSs is clustered, with the densest sites in the central areas of offices, trade, and services. At the same time, it has 
been shown that there is a strong relationship between the site of CWSs that consumers frequently visit and the choice of transportation type. However, there are currently few quantitative studies on the multiple factors affecting the location of CWSs.

In this paper, we analyze the geographic distribution of CWSs and the multiple factors that influence the location of CWSs. This will help us to further understand the spatial distribution pattern of the new type of office space and guide the scientific site selection and planning layout of CWSs in urban cities. First, we expound the development of the co-working industry in China and analyze the distribution characteristics of CWSs in Hangzhou as a typical case. Then, we innovatively construct an indicator system of influencing factors from five aspects, including traffic conditions, the convenience of life, regional business atmosphere, regional innovation environment, and rental cost. Finally, we conduct an empirical analysis of CWSs in Hangzhou, and reveal the influence mechanism of different factors on the site selection. As a frontier city for the development of CWSs in China, the conclusions drawn from Hangzhou are also universal across the country. This study is expected to contribute to urban planning by providing a valuable reference for development of the co-working industry.

\section{Development of CWSs in China and Related Policy Support}

The first CWS in China appeared in 2007 and is located on Yongiia Road, Shanghai. Its purpose is to provide meeting and office space for entrepreneurs in design and art [36]. Based on multiple reasons, such as the rising tide of entrepreneurship, the diversification of demand for new office space, and the transformation of office product forms, the domestic co-working industry entered a period of rapid development in 2015 [37]. Hundreds of companies represented by Kr Space, Ucommune, Mydreamplus, and Nashwork were established in just a few years. CWSs are mainly concentrated in first-tier cities such as Beijing, Shanghai, Guangzhou, and Shenzhen, occupying nearly $80 \%$ of the domestic coworking office market share. Furthermore, CWSs have gradually expanded to new first-tier cities such as Chengdu, Changsha, Hangzhou, and Nanjing in recent years.

According to the report on China's co-working market by iiMedia Research Group [38], it can be found that from 2016 to 2019 China's co-working industry was in a stage of rapid development, with an average annual growth rate of over $100 \%$. In 2020, due to the impact of COVID-19, the growth rate of the market dropped significantly. The entire industry has undergone a profound reshuffle, gradually shifting from large-scale expansion to a stage of delicate operation, and the trend of differentiation between brands is apparent. At the end of 2020, the total operating area of CWSs nationwide exceeded 30 million square meters, and the industry market scale reached 136.82 billion yuan. The industry market scale will continue to grow in the next few years, and it is expected to exceed 200 billion yuan by 2022. China is gradually evolving into one of the largest markets in the world. At the same time, according to the relevant data of the Chinese Academy of Social Sciences, the number of newly registered market entities nationwide in 2020 is 27.354 million, an increase of $12.8 \%$ over last year. Various industries have entered a period of full recovery after the epidemic [39]. The emergence of numerous new companies has brought about large-scale office demand, which provides the necessary objective conditions for the development of CWSs.

The development of CWSs in China has greatly benefited from the domestic entrepreneurial wave of "mass entrepreneurship and innovation." In September 2015, the State Council issued guidance on accelerating the construction of an innovation support platform [40], in which several key tasks around crowd creation were proposed, encouraging the public and the capital market to provide the platform, financial services, etc. As a particular innovation space, the CWS has developed by leaps and bounds after the policy was promulgated [10]. In addition, one of the most important reasons why the CWS can attract a large number of small and medium-sized enterprises is that it provides value-added services such as industrial and commercial registration. As early as March 2014, the State Council issued a reform plan related to the registered capital registration system [41], in which the minimum registered capital limit for many types of companies 
was removed. Furthermore, a reform of the registration system for residences (business premises) has been implemented, allowing "one license for multiple sites" and "multiple licenses at one site." The reform of this system has greatly lowered the company's entry barriers and promoted the growth of the number of start-up teams. Furthermore, it has also allowed the CWS to be registered as a residence for multiple companies, something which has become a favorable condition for attracting many micro-enterprises and individual entrepreneurs to settle in.

On the whole, the support from top-level policies has dramatically stimulated the entrepreneurial enthusiasm of the crowd, thereby driving the rapid expansion of the CWS market. At the same time, local governments at all levels have successively introduced a series of preferential tax policies and fiscal subsidy policies, which, to a large extent, have helped the growth of CWSs and their settled enterprises. Taking Hangzhou as an example, the "Outline of the Thirteenth Five-Year Plan for National Economic and Social Development of Hangzhou" proposed to promote Hangzhou and to build an internationally influential internet entrepreneurship and innovation center [42], leading to a large upgrade of the facilities for innovation and entrepreneurship. Specific measures can be divided into the following three categories: the first is the implementation of various recruitment plans to attract high-level talent to settle in Hangzhou with generous material rewards; the second is to focus on the cultivation of innovative companies, with the government granting funds for project subsidies, rent subsidies, and patent sales subsidies to start-ups that settle in crowd-creation spaces, technology business incubators and other technology platforms; the third is strengthening the building economy and increasing the enthusiasm of CWSs in the spatial layout of such buildings by offering rental discounts to companies that settle in key buildings, and implementing a mechanism to link building owners' incentives and financial contributions.

\section{Research Method and Data}

\subsection{Research Area}

As one of the cities with the most developed private economies in China, Hangzhou has become a focal city for co-working operators to expand their business. In the past three years, with the rapid rise of the internet economy, the number of enterprises in Hangzhou has maintained rapid growth, with a total of 274,100 new small and micro enterprises. The resulting large-scale office demand provides opportunities for the development of CWSs. The co-working market in Hangzhou has been showing explosive growth, with the supply of CWSs exceeding 300,000 square meters. Overseas co-working enterprises represented by Regus and Servcorp entered Hangzhou earlier and seized market opportunities, while domestic enterprises represented by $\mathrm{Kr}$ Space have also accelerated their deployment in Hangzhou after a new round of financing. In addition, a group of local co-working brands in Hangzhou, represented by Will Space, have also emerged on the market.

The research area covers eight administrative districts of Hangzhou, including Shangcheng District, Gongshu District, Xihu District, Binjiang District, Xiaoshan District, Yuhang District, Linping District, and Qiantang District (Figure 1). These administrative districts make up the main urban area of Hangzhou. During acquisition of the data all CWSs were found to be distributed in these eight regions. 


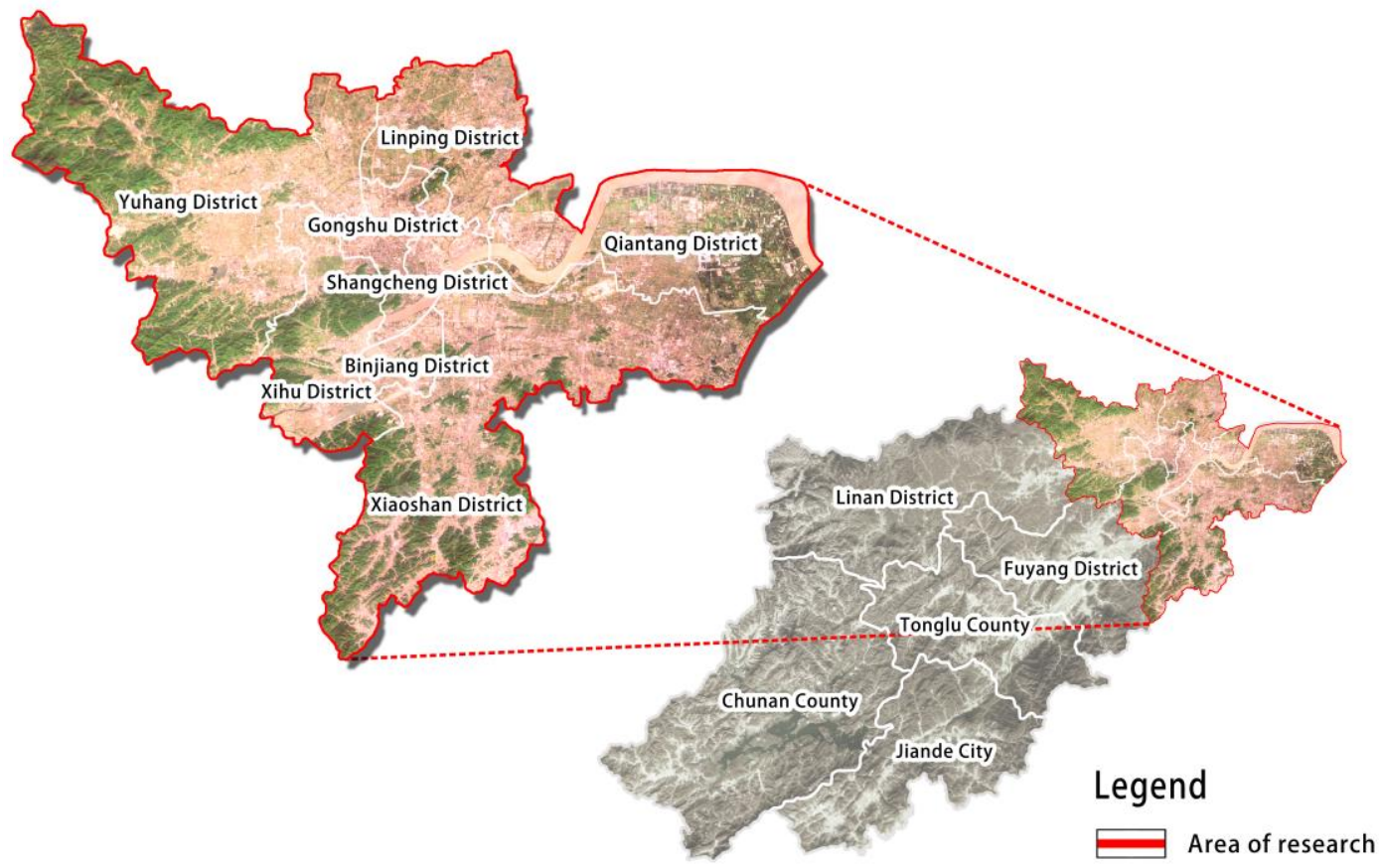

Figure 1. Map of Hangzhou and the research area.

\subsection{Research Method}

\subsubsection{Data Collection}

There are three ways to collect data. One is the compilation of publicly available information on the internet. The information of CWSs in this study comes from various office rental websites, such as the "51 banban" website (https:/ / hz.51banban.com/gongwei/ (accessed on 1 December 2021)). As of December 2021, there are 301 CWSs within the research area. The second is to crawl point of interest (POI) data. Second the POI data involved in this research, such as transportation facilities, business facilities, life service facilities, and innovative space facilities are crawled based on the Baidu map open platform using Python. The third method is to crawl web page data, with house-price data in this study obtained through the use of a collector named "Octoparse" that can crawl second-hand housing price information on the "Fang Tianxia" website (https: / / www1.fang.com/ (accessed on 1 December 2021)). The above data have been screened, deduplicated, inspected, verified, and corrected.

\subsubsection{Data Analysis}

In Section 4, we use the kernel density analysis tool of ArcGIS to carry out a continuity simulation calculation for the density distribution of the data points of CWSs, which visually reflects the overall aggregation situation in the geographical space. It can be used to study the distribution characteristics of CWSs in Hangzhou.

In Section 5, three data analysis methods are used. One is to use the buffer tool of ArcGIS to establish a circular buffer area centered on the data points of CWSs and filter the number of transportation facilities and living service facilities located nearby, this is used to analyze the traffic conditions and living convenience of CWSs. The second is to use the grid tool of ArcGIS to divide the $1 \mathrm{~km} \times 1 \mathrm{~km}$ grid of the research area, the density of business facilities and innovative facilities within the unit grid is then calculated to analyze the regional business atmosphere and innovation environment. The third method is to use the buffer tool of ArcGIS to filter out the surrounding communities and calculate the average second-hand housing prices of these communities, to analyze the land price cost of CWSs. 


\subsubsection{Indicator Weight Calculation}

In Section 5, we use the entropy weight method to calculate the weights of the influencing factors of Hangzhou CWSs' site selection. The entropy weight method determines the weight of each indicator according to the amount of useful information provided by the observation value of each index, and then establishes a multi-index evaluation model based on entropy, so as to obtain a more objective evaluation result. The research on the entropy weight method is relatively mature. It has been widely used in the site analysis of hotels, banks, passenger stations, logistics centers, etc. [43-48], and its feasibility is verified by examples. In the study of factors influencing the site selection of CWSs, it is assumed that there are $n$ indicators and m evaluation objects to form the original data matrix:

$$
\mathrm{X}=\left[\begin{array}{ccc}
x_{11} & \cdots & x_{1 n} \\
\vdots & \ddots & \vdots \\
x_{m 1} & \cdots & x_{m n}
\end{array}\right]
$$

In the formula, $i=1,2,3, \ldots, m ; j=1,2,3, \ldots, n ; x_{i j}$ is the corresponding value of the $i$-th evaluation object under the $j$-th indicator.

Standardize the data of each indicator, assuming that the value of the standardized data of each indicator is:

$$
Y_{11}, Y_{12}, Y_{13}, \ldots \ldots, Y_{m n}
$$

So,

$$
Y_{i j}=\frac{x_{i j}-\min \left(x_{i}\right)}{\max \left(x_{i}\right)-\min \left(x_{i}\right)}
$$

Calculate the characteristic proportion of the $i$-th evaluation indicator under the $j$-th indicator:

$$
P_{i j}=\frac{W_{i j}}{\sum_{i=1}^{m} W_{i j}}, \sum_{i=1}^{m} W_{i j}>0
$$

If $P_{i j}=0$, define $\lim _{P_{i j} \rightarrow 0} P_{i j} \ln P_{i j}=0$. Calculate the information entropy of the $j$-th indicator:

$$
E_{j}=-\mathrm{k} \sum_{i=1}^{m} P_{i j} \cdot \ln P_{i j}
$$

In the formula, $\mathrm{k}$ is the coefficient of entropy, usually $\mathrm{k}=1 / \mathrm{lnm}$, and the weight of indicator corresponding to each influencing factor can be further obtained by the following formula:

$$
Z_{j}=\frac{1-E_{j}}{\sum_{1}^{n} 1-E_{j}}
$$

\section{Distribution Characteristics of CWSs in Hangzhou}

According to quantitative statistics (Table 1), most CWSs are located in the relatively mature downtown area of Hangzhou. Among these, Gongshu District has the largest number of CWSs, followed by Binjiang District, Xihu District, and Shangcheng District, with more than 50 spaces. Yuhang District, Xiaoshan District, and Qiantang District in the periphery have few, while Linping District has the least number of spots, and the difference is noticeable. In comparison, the Gongshu District, Shangcheng District, and other central urban areas, based on the advantages of the complete transportation network, rich service facilities, convenient life, and incentive systems formed by long-term development experience, have attracted more CWSs to settle in. However, along with the comprehensive development of new urban areas, the capital, enterprises, and human resources of Yuhang District, Xiaoshan District, and other peripheral urban areas have gradually accumulated. This also drives more and more co-working enterprises to choose sites in these areas. 
Table 1. Statistics on the number of CWSs in Hangzhou.

\begin{tabular}{ccc}
\hline Administrative District & Number of CWSs & Percentage \\
\hline Shangcheng District & 51 & $16.89 \%$ \\
Gongshu District & 63 & $20.86 \%$ \\
Xihu District & 58 & $19.21 \%$ \\
Binjiang District & 61 & $20.53 \%$ \\
Xiaoshan District & 21 & $6.95 \%$ \\
Yuhang District & 23 & $7.62 \%$ \\
Linping District & 6 & $1.99 \%$ \\
Qiantang District & 18 & $5.96 \%$ \\
Total & 301 & $100 \%$ \\
\hline
\end{tabular}

We used the kernel density analysis tool in ArcGIS software to analyze the acquired geographic data points of CWSs and "natural discontinuities" to classify and identify them based on the inherent natural grouping in the data, allowing us to maximize the difference between the various types [49]. The analysis result is shown in Figure 2. The redder the color, the higher the concentration of CWSs. Overall, the distribution of CWSs in Hangzhou presents a multi-center pattern. Among them, the three core business districts of Wulin CBD, Huanglong CBD, Qianjiang New Town CBD, and Binjiang High-tech Zone are the areas with the highest concentration of CWSs. Sub-level agglomeration centers have appeared in Qianjiang Century City CBD, Future Sci-Tech City CBD, Xiasha Higher Education Park, and other areas. The supply of high-quality office buildings in these areas is relatively sufficient, and there are a large number of business offices, hotel apartments, conventions, and cultural and entertainment facilities, which not only provide high-quality building space but also create an overall atmosphere of strong entrepreneurial vitality, something that is convenient for the development of modern business offices [50]. In addition, there is also a tiny fraction of CWSs distributed in featured towns, schools, and communities.

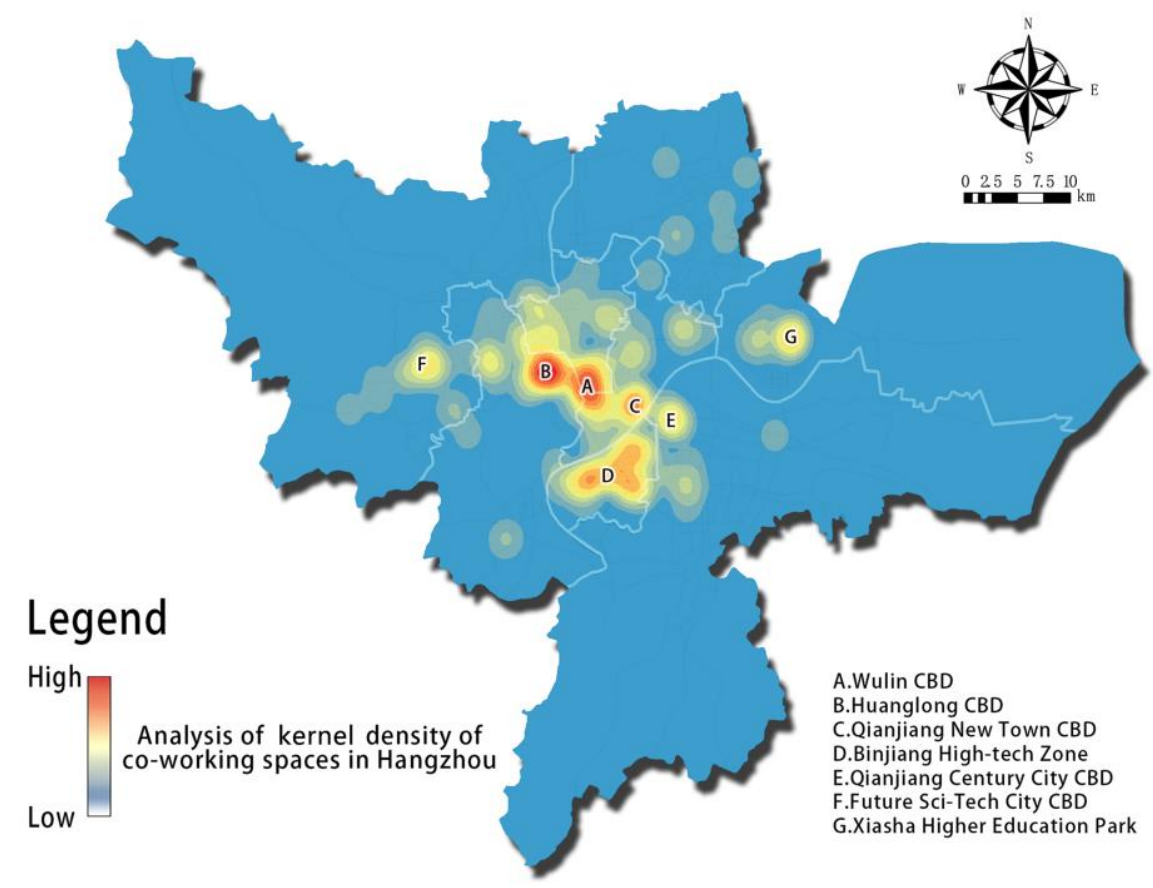

Figure 2. Analysis of kernel density of CWSs in Hangzhou.

\section{Analysis of Factors Affecting the Site Selection of CWSs}

\subsection{Influencing Factors and Indicator Selection}

Through the above analysis of the distribution characteristics of CWSs in Hangzhou, we found that most CWSs are located in the old urban areas of Hangzhou, which have 
denser transportation networks and public transportation stations, as well as a large number of living service facilities. The agglomeration centers of CWSs are also geographically consistent with the major business districts in Hangzhou, which have a strong business atmosphere. In combination with other scholars' research, we also found that the location of office space is closely related to transportation convenience and rent [34,51]. Moreover, CWS is a form of commercial service that meets the needs of users as much as possible. According to a report on China's co-working market by iiMedia Research Group [38], it can be found that, among the users of CWSs, people engaged in the internet, finance, cultural and creative industries accounted for a relatively high proportion. These industries often also put forward higher requirements for business cooperation and innovation activities in the region. Therefore, we determined the factors affecting the site selection of CWSs into five aspects, including traffic conditions, the convenience of life, regional business atmosphere, regional innovation, and rental cost.

\subsubsection{Traffic Conditions}

Urban road traffic has vital flexibility and convenience, and the layout of the urban road system has a robust guiding role in the direction of urban development. The road transportation network is the key to gathering various production factors such as people flow, financial resources, and information. It has also become an important consideration factor affecting the site selection of CWSs because the efficient and convenient road network can reduce business travel time and increase the occupancy rate of office space. At the same time, the public transportation system represented by subway and bus has the characteristics of large capacity, safety and punctuality, low prices, and green environmental protection, which can effectively break the geographical area restrictions and have a profound impact on the land use structure, the distribution of residences, and real estate development along the subway and bus lines [52-54]. Zhen et al. [55] empirically analyzed how rail transit interchange stations have a positive guiding role in the location of office spaces, and found that, as the coverage range of interchange stations expands, the number of high-level office clusters covered by them also gradually increases. Therefore, the indicators selected in this study in terms of traffic conditions mainly include main urban roads and public transportation (subway and bus).

\subsubsection{The Convenience of Life}

The convenience of life is the fundamental aspiration of urban people. With the current blurring of the boundaries between work and life, the convenience of life service facilities has also become an essential factor in the choice of office space for office workers, which in turn affects the site of CWSs. In terms of the selection of indicators for the convenience of life, Ying et al. [56] chose catering, education, medical care, culture, leisure, and entertainment facilities to evaluate of the convenience of residents in the main urban area of Wuhan. Zhang et al. [57] found in the analysis of Beijing urban office space satisfaction that the spatial distribution characteristics of the fulfillment of the office crowd are closely related to the spatial distribution of commercial supporting facilities. Based on this, combined with the features of the user population of CWSs, the indicators selected in this study for the convenience of life mainly include catering facilities, recreational facilities, and medical facilities.

\subsubsection{Regional Business Atmosphere}

The urban business district is a product of the developed city economy, and it is also the concentrated area of the city's high-end productive service industry, with a strong business atmosphere. In particular, there are a large number of high-quality business office buildings in the area, making it an excellent choice for the location of CWSs. Startup entrepreneurs can take advantage of low-cost CWSs' rental fees, enjoy perfect office facilities and high-quality meeting spaces in the urban business district, thereby enhancing their enthusiasm for office work, and even contributing to successful business negotiations with partners. At the same time, users of the CWSs can also participate in frequent training, 
salons and other activities held in the business district, so as to learn professional business knowledge and expand their social circles. As a result, more and more CWSs sprout in business centers. Therefore, an intense business office atmosphere has also become the site preference of CWSs. This study selects the number of business office buildings within a specific range as an indicator to measure the regional business atmosphere.

\subsubsection{Regional Innovation Environment}

From the perspective of a static environment, the regional innovation environment represents the physical environment that carries the transportation, public services, information network and other infrastructure required for innovation activities. Moreover, the innovation environment is also a dynamic development process. It is a relatively stable cooperation and communication system that is formed based on the long-term formal or informal relationships between innovation entities [58]. Due to its entrepreneurial incubation function, the CWS can almost be regarded as a new type of innovative cyberspace node that allows different participants to collect, link, and share information. The innovation environment affects the innovation activities of CWSs to different degrees. In the study of regional innovation environments, Zhao et al. [59] analyzed Hangzhou's innovation system at the two levels of innovative enterprises and innovation parks. Innovative enterprises cover industries such as internet, technology, e-commerce, and cultural creativity, while innovation parks are physical carriers of industrial space gathering, including high-tech zones and creative blocks. To a certain extent, the number of innovative enterprises represents the scale of innovation activities and can also reflect the vitality of the innovation environment in the region. Innovation parks, on the other hand, represent the physical environment that carries innovation activities. Therefore, this study selects the density of innovative enterprises and innovation parks within a specific range as indicators to measure the innovation environment of the area where the CWS is located.

\subsubsection{Rental Cost}

The operating costs of CWSs mainly include property rent, decoration costs, and water, electricity, and labor costs in operation. At this stage, most co-working operators adopt the business model of "low-cost overall leasing in, and high-priced leasing after segmentation." The most direct income comes from the leasing difference earned as a "second landlord." Therefore, property rent has become a key factor affecting the site of CWSs. Due to the privacy of property rent, we cannot obtain this data through public information or questionnaires, so this study uses land price as a measure. The land price is essentially the capitalized land rent, which forms the basis of the property rent [60]. The urban bid rent model established by Alonso shows that different land use properties form different bid rent curves, among which commercial and office land are most sensitive to changes in land prices [61]. Moreover, since the land price in China is usually set for a certain district of the city, it cannot accurately represent the land price of CWSs. A large number of domestic empirical studies have shown that there is a positive correlation between land prices and housing prices [62-65]. Therefore, this study uses the average housing prices within $1 \mathrm{~km}$ of CWSs as a substitute.

In summary, on the basis of theoretical research and combined with existing research results, we initially selected five types of influencing factors and ten specific evaluation indicators and formulated statistical radii according to the service radius standards of different facilities, so as to establish an indicator system of factors affecting the site selection of CWSs (Table 2). 
Table 2. Indicator system of factors affecting site selection of CWSs.

\begin{tabular}{|c|c|c|c|c|c|}
\hline Influencing Factor & Evaluation Indicator & $\begin{array}{l}\text { Statistical } \\
\text { Method }\end{array}$ & $\begin{array}{l}\text { Radius } \\
\text { (m) }\end{array}$ & $\begin{array}{l}\text { Evaluation } \\
\text { Unit }\end{array}$ & Indicator Description \\
\hline \multirow{3}{*}{ Traffic conditions (A1) } & Main roads of city (B1) & $1 / 0$ & 500 & $1 / 0$ & $\begin{array}{c}\text { The accessibility of urban } \\
\text { road traffic }\end{array}$ \\
\hline & Subway station (B2) & quantity & 1000 & / & $\begin{array}{l}\text { The convenience of the } \\
\text { subway }\end{array}$ \\
\hline & Bus stop (B3) & quantity & 500 & / & The convenience of the bus \\
\hline \multirow{3}{*}{$\begin{array}{l}\text { The convenience of life } \\
\text { (A2) }\end{array}$} & Catering facilities (B4) & quantity & 500 & / & $\begin{array}{l}\text { The convenience of catering } \\
\text { facilities }\end{array}$ \\
\hline & Recreational facilities (B5) & quantity & 500 & / & $\begin{array}{l}\text { The convenience of } \\
\text { recreational facilities }\end{array}$ \\
\hline & Medical facilities (B6) & quantity & 1000 & / & $\begin{array}{l}\text { The convenience of medical } \\
\text { facilities }\end{array}$ \\
\hline $\begin{array}{l}\text { Regional business } \\
\text { atmosphere (A3) }\end{array}$ & Business office building (B7) & density & 1000 & $/ \mathrm{km}^{2}$ & $\begin{array}{c}\text { The convergence of the } \\
\text { business industry in the } \\
\text { region }\end{array}$ \\
\hline \multirow{2}{*}{$\begin{array}{l}\text { Regional innovation } \\
\text { environment (A4) }\end{array}$} & Innovative enterprise (B8) & density & 1000 & $/ \mathrm{km}^{2}$ & $\begin{array}{l}\text { The concentration of } \\
\text { innovative enterprises in the } \\
\text { region }\end{array}$ \\
\hline & Innovation park (B9) & density & 1000 & $/ \mathrm{km}^{2}$ & $\begin{array}{l}\text { The concentration of } \\
\text { innovation parks in the } \\
\text { region }\end{array}$ \\
\hline Rental cost (A5) & Property rent (B10) & land price & 1000 & yuan $/ \mathrm{m}^{2}$ & $\begin{array}{l}\text { Land price (replaced by } \\
\text { average housing prices) } \\
\text { affects rental cost }\end{array}$ \\
\hline
\end{tabular}

\subsection{An Empirical Study on Site Selection of CWSs in Hangzhou}

\subsubsection{Analysis of Each Influencing Factor}

Based on the indicator system of factors affecting CWSs' site selection as mentioned above, a comprehensive evaluation of the site of 301 CWSs in Hangzhou was carried out using ArcGIS software. This can be inferred by calculation:

(1) By analyzing the traffic conditions of CWSs in Hangzhou, it is found that $94.02 \%$ of CWSs in the research area are located within $500 \mathrm{~m}$ of the city's main roads (Figure 3a); $87.71 \%$ of CWSs are located within $1000 \mathrm{~m}$ of the subway station, and the number of subway stations around CWSs is 1.8 on average (Figure 3b); $98.67 \%$ of CWSs are located within $500 \mathrm{~m}$ of the bus stop, and the number of bus stops around CWSs is 6.3 on average (Figure 3c). It can be concluded that CWSs in Hangzhou generally have high accessibility of urban road traffic, and the public transportation around them is also very convenient. 


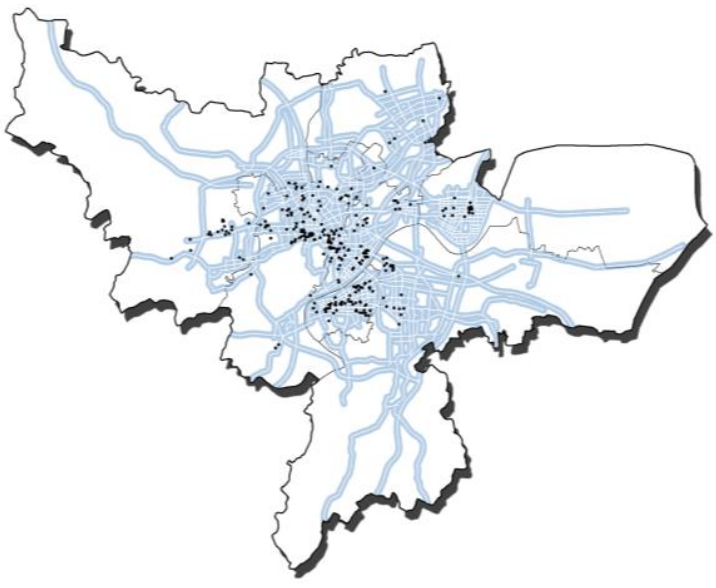

(a) Co-working spaces within 500 meters of the city's main roads

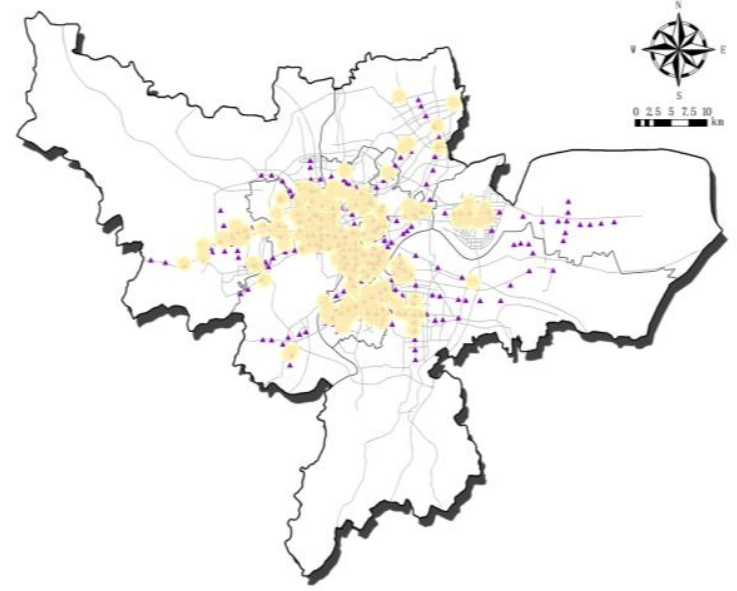

(b) Subway stations within 1000 meters of co-working spaces

\section{Legend}

\footnotetext{
Within 500 meters of the city' $s$ main roads

- Co-working spaces Within 1000 meters of co-working spaces

$\Delta$ Subway stations

Within 500 meters of co-working spaces

$\Delta$ Bus stops
}

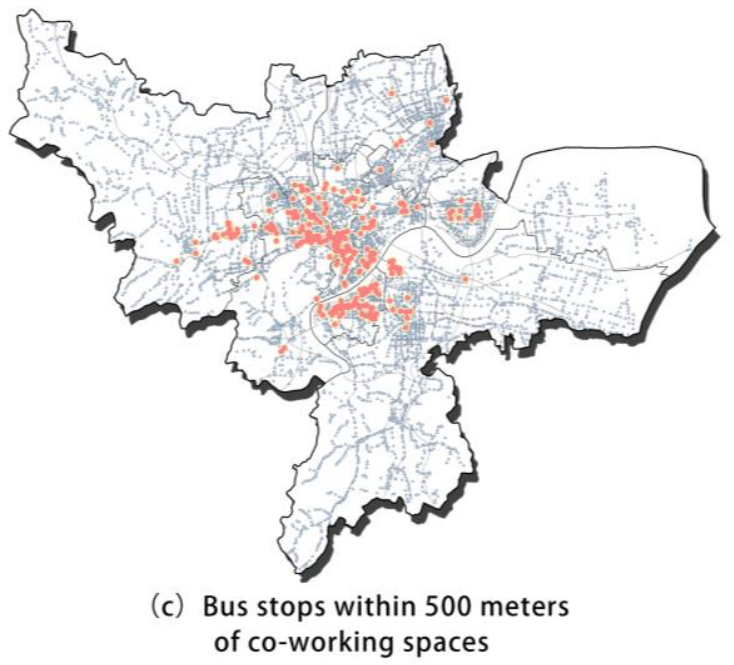

Figure 3. Analysis of the traffic conditions of CWSs in Hangzhou. (a) CWSs within $500 \mathrm{~m}$ of the city's main roads, (b) Subway stations within $1000 \mathrm{~m}$ of CWSs, (c) Bus stops within $500 \mathrm{~m}$ of CWSs.

(2) We analyzed the convenience of life of CWSs in Hangzhou and found that there are an average of 152 catering facilities (Figure $4 \mathrm{a}$ ) and 22 recreational facilities (Figure $4 \mathrm{~b}$ ) within $500 \mathrm{~m}$ of CWSs; there are an average of 26 medical facilities within $1000 \mathrm{~m}$ of CWSs (Figure 4c). These facilities are rich in variety, covering catering, entertainment, leisure, culture, sports, medical care, etc., and so can meet the basic life needs of office workers.

(3) We analyzed the regional business atmosphere of CWSs in Hangzhou by calculating the density of business office buildings within a specific range (Figure 5) and found that most CWSs are located in areas with dense business office buildings. Within $1 \mathrm{~km}^{2}$ of CWSs, the average density of business office buildings is $14 / \mathrm{km}^{2}$, and the highest density is $52 / \mathrm{km}^{2}$. It can be seen that the business facilities near CWSs are highly clustered, and the business atmosphere is relatively strong. 


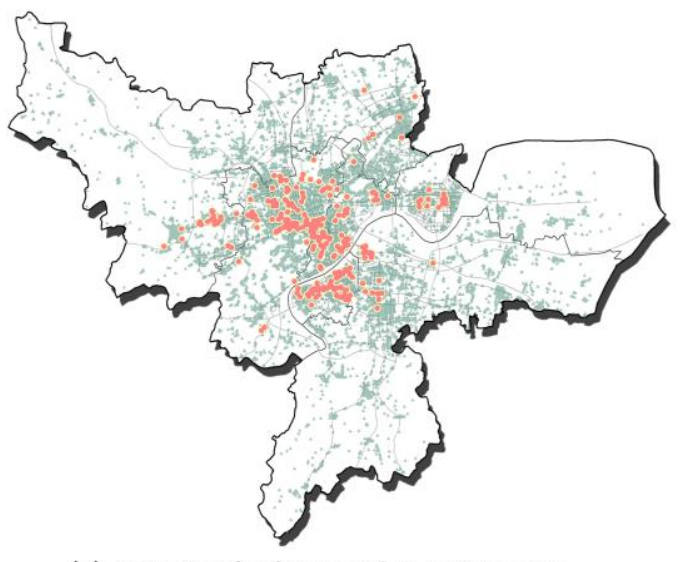

(a) Catering facilities within 500 meters of co-working spaces

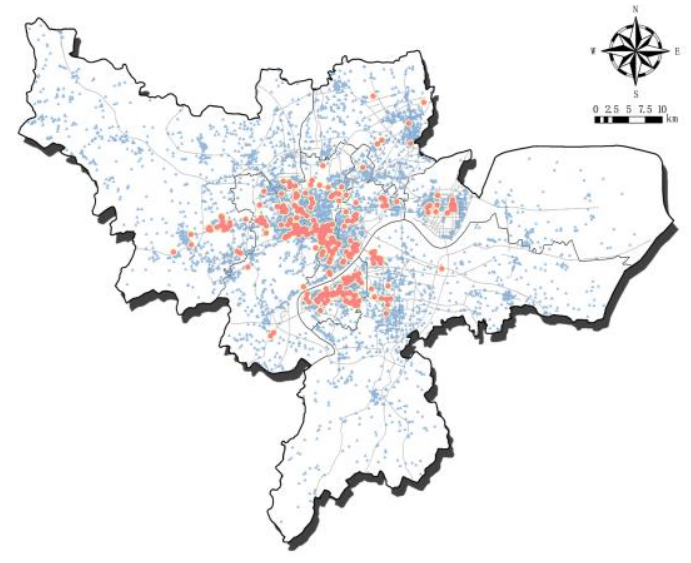

(b) Recreational facilities within 500 meters of co-working spaces

\section{Legend}

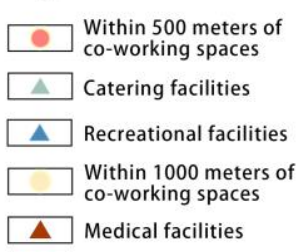

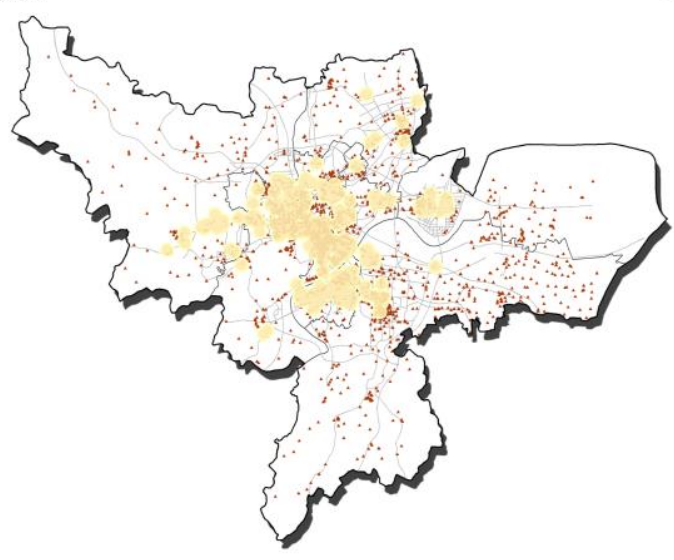

(c) Medical facilities within 1000 meters of co-working spaces

Figure 4. Analysis of the convenience of life of CWSs in Hangzhou. (a) Catering facilities within $500 \mathrm{~m}$ of CWSs, (b) Recreational facilities within $500 \mathrm{~m}$ of CWSs, (c) Medical facilities within $1000 \mathrm{~m}$ of CWSs.

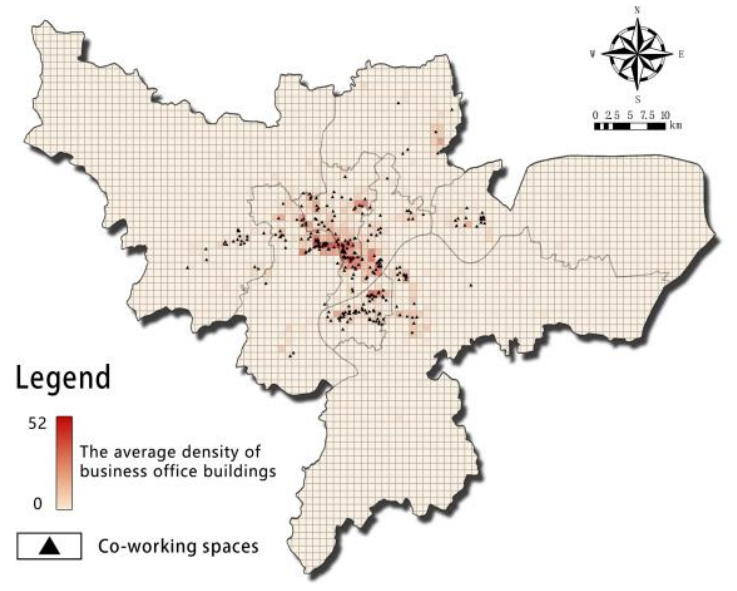

Figure 5. Analysis of the regional business atmosphere of CWSs in Hangzhou.

(4) Based on two evaluation indicators (innovative enterprise density and innovation park density), we analyzed the regional innovation environment of CWSs in Hangzhou. We found that within $1 \mathrm{~km}^{2}$ of CWSs, the average density of innovative enterprises is $29 / \mathrm{km}^{2}$, and the highest density can reach $288 / \mathrm{km}^{2}$ (Figure 6a); the average density of innovation parks is $1.2 / \mathrm{km}^{2}$, and the highest density can reach $8 / \mathrm{km}^{2}$ (Figure $6 \mathrm{~b}$ ). It can be concluded 
that the area where a CWS is located forms a strong innovation agglomeration effect and a powerful innovation atmosphere.

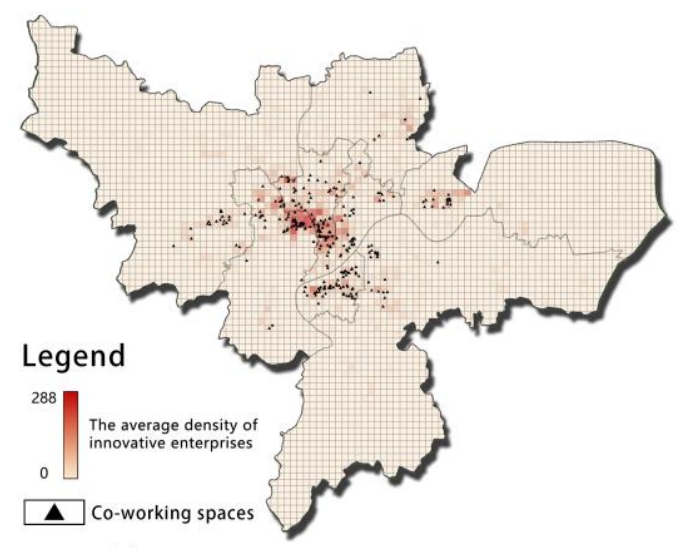

(a) The average density of innovative enterprises in Hangzhou

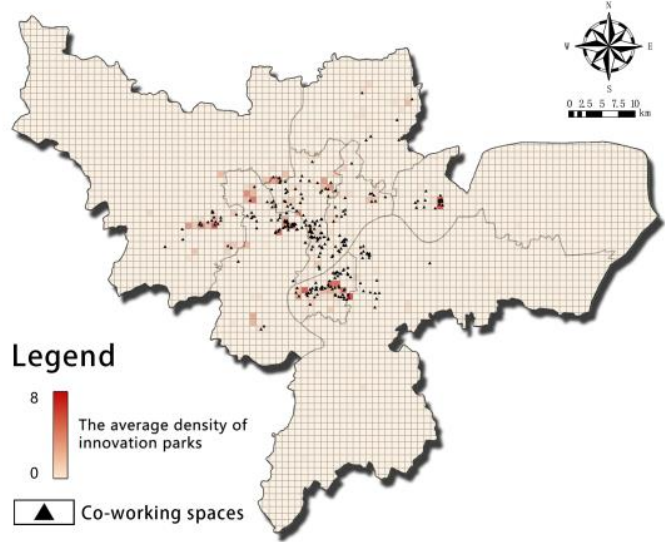

(b) The average density of innovation parks in Hangzhou

Figure 6. Analysis of the regional innovation environment of CWSs in Hangzhou. (a) The average density of innovative enterprises in Hangzhou, (b) The average density of innovation parks in Hangzhou.

(5) We infer the level of the rental cost of CWSs by analyzing the surrounding housing prices (Figure 7). It can be seen that the housing prices in the area where CWSs are located are at a relatively high level. Within $1000 \mathrm{~m}$ of CWSs, the average price of second-hand housing in the community is as high as $44,437 \mathrm{yuan} / \mathrm{m}^{2}$. To some extent, this can reflect the preference of CWSs to be located in areas with high land prices and high rental costs.

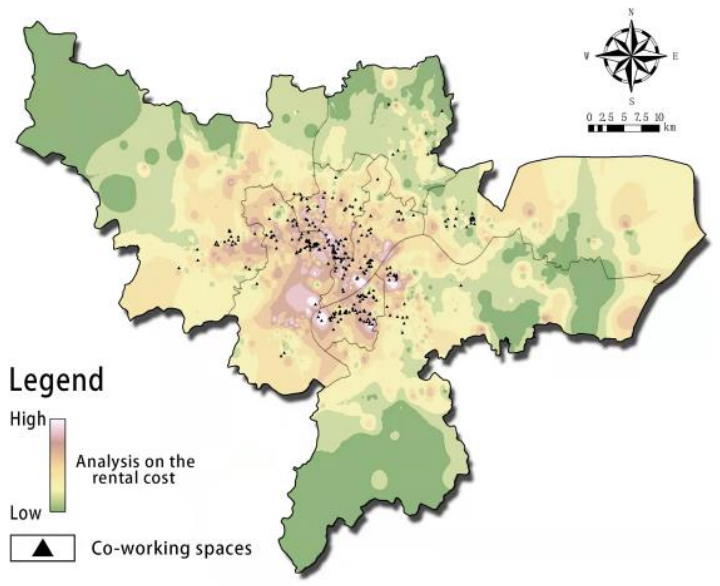

Figure 7. Analysis of the rental cost of CWSs in Hangzhou.

\subsubsection{Weight Calculation of Each Influencing Factor}

Based on the statistical results of 301 CWSs, a multi-indicator evaluation model based on entropy was established, and the weights of different influencing factors in the site selection of CWSs in Hangzhou were calculated (Table 3). Among the five influencing factors, the regional innovation environment factor has the most prominent weigh at 0.3941 , this is followed by the convenience of life, regional business atmosphere, and traffic conditions, with weights of $0.3147,0.1352$, and 0.1171 , respectively. The least influential factor is rental cost, which is only 0.0389. Among the ten specific evaluation indicators, the indicator "Density of innovative enterprises within $1 \mathrm{~km} \times 1 \mathrm{~km}$ " has the highest weight at 0.2466; the indicator "Whether it is within $500 \mathrm{~m}$ of the city's main roads" has the lowest weight, only 0.0195 . 
Table 3. Weights of different factors influencing the site selection of CWSs in Hangzhou.

\begin{tabular}{ccc}
\hline Influencing Factor & Evaluation Indicator & Weight \\
\hline Traffic Conditions (A1) & Main roads of city (B1) & 0.0195 \\
$(0.1171)$ & Subway station (B2) & 0.0596 \\
& Bus stop (B3) & 0.0380 \\
\hline The convenience of life (A2) & Catering facilities (B4) & 0.0904 \\
$(0.3147)$ & Recreational facilities (B5) & 0.0808 \\
& Medical facilities (B6) & 0.1435 \\
\hline Regional business atmosphere (A3) & Business office building (B7) & 0.1352 \\
\hline Regional innovation environment (A4) & Innovative enterprise (B8) & 0.2466 \\
$(0.3941)$ & Innovation park (B9) & 0.1475 \\
\hline Rental cost (A5) & Property rent (B10) & 0.0389 \\
\hline
\end{tabular}

\section{Discussion and Suggestions}

When a co-working company begins to expand its business in a certain city, its executives will choose the location of CWSs. We attempt to explore the factors that influence the site selection by analyzing the distribution characteristics of existing CWSs. From the above research results, we find that the effects of several influencing factors on site selection are significantly different, and the reasons for these differences are discussed below.

The factor of regional innovation environment plays a vital role in the site selection of CWSs in Hangzhou, which intuitively reflects the high degree of dependence of the CWS on innovative elements. This relationship is closely related to the innovative characteristics of the CWS itself, because, to a certain extent, it can be regarded as an incubator for innovative enterprises and innovative talents. Therefore, based on the self-development of the CWS and the growth of its users, major co-working brand operators will prefer to choose sites in an urban area with an intense atmosphere of innovation and entrepreneurship. As one of the most prosperous and developed cities in China's internet industry, Hangzhou has significant advantages in terms of innovation conditions, which further magnifies the impact of the innovation environment on site selection.

The convenience of life has a high degree of influence on the site selection, which is inseparable from the user population of spaces. Since the CWS was initially established to serve individual workers and micro-enterprises, the age structure of the user population is often mainly young people. Most of them are still in the early stage of entrepreneurship, so there is a more robust demand for catering, leisure, entertainment, and other service facilities, making this factor particularly important.

The regional business atmosphere and traffic conditions have relatively little impact on the site selection. In terms of regional business atmosphere, office buildings in the core business districts of cities are often concentrated, and the business atmosphere is intense. However, the vacancy rate of buildings in these areas is relatively low, which causes difficulties for co-working operators to lease large-scale office space. In addition, some industrial parks, universities, and residential communities can also provide the space conditions required for co-working. Therefore, business office buildings are not the only resident of CWSs, and the influence of the regional business atmosphere factor is not strong. In terms of traffic conditions, compared to main roads of the city, public transportation based on subway and bus has a more significant impact on the site selection. This is mainly due to the dense public transportation network in the main urban area of Hangzhou where commuting by public transportation is the first choice for CWSs' users.

Rental cost is the most minor factor affecting the site selection, something which can be attributed to the diversified profitability of CWSs. Although the most direct income of CWSs comes from the lease price difference, many co-working enterprises have explored new value-added derivative services after years of development, these include brand franchises, 
membership services, equity investment, and financial training. These diversified valueadded service revenues help break through the original profitability bottleneck. Therefore, rental cost is no longer a key factor affecting the site selection of CWSs.

Through this research, we think the following suggestions can be considered in the site selection of CWSs: (1) Before selecting a site, it is necessary to evaluate the dependence of target users on business, capital, information and other resources. Co-working operators need to grasp the guidance of regional policies, so as to create more investment and development opportunities for start-ups. (2) Urban CBD is the preferred choice for the site selection of CWSs. It not only has a good economic effect on office buildings and can continuously attract talents and businesses, but also has multiple public transportation facilities and living service facilities in the area, which can well meet the needs of employees' commuting and daily life. (3) Nowadays, a number of second and third tier cities have formed several powerful technological innovation clusters while showing great economic vitality. If CWSs are located in these clusters which, by including places such as internet industrial parks and higher education parks, have a strong atmosphere of innovation, it will help to form a benign interaction between the CWSs' users and surrounding hightech enterprises, thereby accelerating the transformation of technological achievements. (4) With the blurring of the boundaries between work, life, and entertainment, the site of CWSs should also consider their integration with co-living spaces and commercial spaces, relying on the vibrant atmosphere of youth apartments, hotels, shopping centers, and other areas to attract and exploit potential users. On this basis, CSW operators can adopt a diversified profit model to further integrate land, corporate, and community resources, thereby expanding the industrial chain.

\section{Conclusions}

To some extent, the original intention of the CWS was to innovate and supplement the traditional office leasing model and help promote the inventory and transformation of office buildings. More and more practices have also shown that, as a new form of spatial economic activity, CWS has played an essential role in the development of the regional economy and the revival of urban space. In the new round of urban district renewal, CWS can rely on its comprehensive professional office services to quickly focus on social capital and attract talents. It not only realizes the sustainable use of resources, but also generates diversified needs, thereby continuously improving the economic benefits of surrounding areas.

Based on previous research, we innovatively proposed an indicator system for the influencing factors of CWSs' site selection and conducted an empirical analysis. This study takes CWSs in Hangzhou as the research object and explores their distribution characteristics and influencing factors. The results show that CWSs in Hangzhou generally present a multi-center distribution pattern, gradually spreading from the central urban area to the peripheral regions. Based on the development positioning and customer needs of different types of CWSs, the site is also affected by various indicators. The most crucial factor is the regional innovation environment, followed by the convenience of life, regional business atmosphere, and traffic conditions, while rental cost has the most negligible impact on site selection.

In addition, this study has certain limitations. First, this study only explores the factors affecting the site selection of CWSs in Hangzhou, and the selected sample size is limited, with particular geographical characteristics. It is necessary to expand the scope of research further and conduct comparative verification of the site selection system for CWSs in different cities. Secondly, since the CWS industry has not yet formed a complete development system in China, this study only combines the relevant research literature and the distribution characteristics of CWSs in the selection of influencing factors. The completeness of the weight needs to be further verified. Therefore, the perspectives of experts, CWSs' founders and users should be introduced through questionnaires and interviews in future research, so that more scientific indicators and variables underlying influencing factors can be selected. Furthermore, due to the limited availability of data, this 
study did not evaluate the success of CWSs' site selection. Therefore, performance reports or occupancy rates for individual sites can be introduced in micro-scale studies to indicate that the site selection is successful.

Author Contributions: Conceptualization, W.W. and J.L.; methodology, W.W.; data collection, J.N.; data analysis, J.L.; validation, W.W. and J.N.; model, J.L. and J.N.; writing-original draft preparation, J.L., J.N. and W.W. W.W. are responsible for future questions from readers as the corresponding author. All authors have read and agreed to the published version of the manuscript.

Funding: This research was funded by The National Natural Science Foundation of China, grant number 51578482.

Institutional Review Board Statement: Not applicable.

Data Availability Statement: The data are not publicly available due to privacy. The data presented in this paper are available on request from the corresponding author.

Conflicts of Interest: The authors declare no conflict of interest.

\section{References}

1. Harris, S.; Mata, É.; Plepys, A.; Katzeff, C. Sharing is Daring, but is it Sustainable? An Assessment of Sharing Cars, Electric Tools and Offices in Sweden. Resour. Conserv. Recycl. 2021, 170, 105583. [CrossRef]

2. Lou, L.; Li, L.; Yang, S.B.; Koh, J. Promoting User Participation of Shared Mobility in the Sharing Economy: Evidence from Chinese Bike Sharing Services. Sustainability 2021, 13, 1533. [CrossRef]

3. Sung, E.; Kim, H.; Lee, D. Why do People Consume and Provide Sharing Economy Accommodation?-A Sustainability Perspective. Sustainability 2018, 10, 2072. [CrossRef]

4. Álvarez-Herranz, A.; Macedo-Ruíz, E. An Evaluation of the Three Pillars of Sustainability in Cities with High Airbnb Presence: A Case Study of the City of Madrid. Sustainability 2021, 13, 3220. [CrossRef]

5. Tescașiu, B.; Epuran, G.; Tecău, A.S.; Chițu, I.B.; Mekinc, J. Innovative Forms of Economy and Sustainable Urban DevelopmentSharing Tourism. Sustainability 2018, 10, 3919. [CrossRef]

6. Liu, P.; Gao, P.; Chu, P. How to Evaluate the Feasibility on Renewables' Sharing Economy in China: A case Study of Uber-like Mode Plus Wind. Renew. Energy 2021, 169, 80-94. [CrossRef]

7. Li, Y.; He, F.; Fang, K.; Liang, J. The Development and Policy Promotion of Sharing Economy-A Case Study of Hangzhou. Zhejiang Soc. Sci. 2017, 107-113. [CrossRef]

8. Wang, J.; Zhen, F.; Feng, J. Research on the Development of Co-Working Space and Its Impact on Innovation in the Information Era. J. Hum. Settl. West China 2015, 30, 48-52. [CrossRef]

9. Davis, D. Vertically Integrated Research: An Unusual Business Model. Archit. Des. 2019, 89, 68-75. [CrossRef]

10. Ding, Y. Research on the Market Situation and Development Trend of Joint Office Space in China. Master's Thesis, Southeast University, Nanjing, China, 2019.

11. Bates, T.W. Community and Collaboration: New Shared Work Places for Evolving Work Practices. Ph.D. Thesis, MIT, Boston, MA, USA, 2011.

12. Parrino, L. Coworking: Assessing the Role of Proximity in Knowledge Exchange. Knowl. Manag. Res. Pract. 2015, 13, $261-271$. [CrossRef]

13. Moriset, B. Building New Places of the Creative Economy: The Rise of Coworking Spaces. In Proceedings of the 2nd Geography of Innovation, International Conference 2014, Utrecht, The Netherlands, 5 March 2014; pp. 18-27.

14. Ross, P.; Ressia, S. Neither Office nor Home: Coworking as an Emerging Workplace Choice. Employ. Relat. Rec. 2015, 15, 42-57. [CrossRef]

15. González-Chouciño, M.A. The Co-Working as a Social Innovation. A Qualitative Study of the Reasons for Creating Co-Working Spaces. Rev. Española Investig. Sociol. 2020, 172, 61-97. [CrossRef]

16. Zhang, T.J.; Cheng, B.Q.; Xia, C.Y. Analysis of Co-working Spaces and Transformation of Existing Plants under the Sharing Economy in Beijing. Ind. Constr. 2018, 48, 83-88. [CrossRef]

17. Manika, S. Transforming Vacant Commercial Spaces: From Localized Hotspots of Urban Shrinkage to "Smart" Co-Working Places. Open J. Soc. Sci. 2020, 8, 86. [CrossRef]

18. Capdevila, I. Knowledge Dynamics in Localized Communities: Coworking Spaces as Microclusters. SSRN Electron. J. 2013. [CrossRef]

19. Zhang, Y.M.; Mao, J.Y. Study on the Innovation and Growth Strategy of Co-Working Space Business Model—Case Study based on URwork. Sci. Technol. Prog. Policy 2017, 34, 1-8. [CrossRef]

20. Liang, Y.B. A Comparative Study on the Spatial Features and Influencing Factors of Shared Office and Traditional Office Rents in Beijing's Fifth Ring Road. Beijing Plan. Rev. 2020, 60-65. Available online: http:/ / qikan.cqvip.com/Qikan/Article/Detail?id=71 01696106 (accessed on 5 December 2021). 
21. Soegoto, E.S.; Hafandi, E.I. Effect of Co-working Space Designs to Business Development and Increasing User Interest. In Proceedings of the International Conference on Informatics, Engineering, Science and Technology, Bandung, Indonesia, 9 May 2018; p. 012024.

22. Ondia, E.P.; Hengrasmee, S.; Chansomsak, S. Spatial Configuration and Users' Behavior in Co-Working Spaces. YBL J. Built Environ. 2018, 6, 20-36. [CrossRef]

23. Nagarathinam, S.; Vasan, A.; Sarangan, V.; Jayaprakash, R.; Sivasubramaniam, A. User placement and Optimal Cooling Energy for Co-working Building Spaces. ACM Trans. Cyber Phys. Syst. 2021, 5, 1-24. [CrossRef]

24. Pang, X.; Zeng, J. Furniture Design for Co-working Space. Packag. Eng. 2021, 42, 212-218. [CrossRef]

25. Liu, J.; Yu, Z.Y. Research on Interior Assembly Design of Co-working Space under the Concept of Green Construction. Art Design 2020, 2, 56-57. [CrossRef]

26. Wang, R.Z.; Huang, Z.H. Research on Design Pattern of Shared Office Space under Non-interactive Relationship. Hunan Packag. 2021, 36, 144-146. [CrossRef]

27. Cai, X.Z. Urban Economics; Nankai University Press: Tianjin, China, 1998; ISBN 9787310011056.

28. Jin, X.Y. Survey and Evaluation of Location Theory in 20 Century by Five Development Stage. Art Design 2004, 24, 294-298. [CrossRef]

29. Weber, A. Theory of the Location of Industries; University of Chicago Press: Chicago, IL, USA, 1929; ISBN 9787100082556.

30. Hamilton, F.E.I.; Townsend, A.R.; Crum, R.E. Contemporary Industrialization: Spatial Analysis and Regional Development. Econ. Geogr. 1979, 55, 257. [CrossRef]

31. Rahman, S.M.; Kabir, A. Factors Influencing Location Choice and Cluster Pattern of Manufacturing Small and Medium Enterprises in Cities: Evidence from Khulna City of Bangladesh. J. Glob. Entrep. Res. 2019, 9, 1-26. [CrossRef]

32. Salinger, J.H. Economic Development Policies through Business Incubation and Co-Working: A Study of San Francisco and New York City. Ph.D. Thesis, Columbia University, New York, NY, USA, 2013.

33. Mariotti, I.; Pacchi, C.; Di Vita, S. Co-working spaces in Milan: Location patterns and urban effects. J. Urban Technol. 2017, 24, 47-66. [CrossRef]

34. Wu, X.J.; Zhang, Y.N.; Liu, Z. Spatial Distribution of Coworking Space in Shanghai. Urban Dev. Stud. 2018, 25, 62-71. [CrossRef]

35. Dianovita, K. The Distribution Pattern of Co-working Space in Jakarta and Determinant Factors of Consumers' Preferences on Location Decision. In Proceedings of the International Conference on Sustainable Design, Engineering, Management and Sciences, Kuala Lumpur, Malaysia, 16-17 October 2019; p. 012018.

36. Dai, W.Q. Research on the Development Status of Co-working in China. Pop. Lit. 2015, 105-106. Available online: https://d.wanfangdata.com.cn/periodical/ChlQZXJpb2RpY2FsQ0hJTmV3UzIwMjExMjMwEg1kend5MjAxNTA0 MDkyGggxNDhqZmx4OQ\%253D\%253D (accessed on 10 December 2021).

37. Zhang, X.L. Research on the Design of Local Co-working Space. Master's Thesis, Central Academy of Fine Art, Beijing, China, 2016.

38. 2020-2021 China Coworking Office Industry White Paper. Available online: https://www.iimedia.cn/c400/69264.html (accessed on 25 February 2020).

39. 2020 China Enterprise Development Data Annual Report. Available online: https://www.meadin.com/yj/225236.html (accessed on 3 March 2021).

40. Guiding Opinions on Accelerating the Construction of a Supporting Platform for Mass Entrepreneurship and Innovation; State Council of China: Beijing, China, 2015.

41. Registered Capital Registration System Reform Plan; State Council of China: Beijing, China, 2014. Available online: http:/ /www.gov. cn/zhengce/content/2014-02/18/content_8642.htm (accessed on 10 November 2021).

42. Outline of the 13th Five-Year Plan for the National Economic and Social Development of Hangzhou; Hangzhou Municipal People's Government: Hangzhou, China, 2016. Available online: http://www.hangzhou.gov.cn/art/2016/6/1/art_1176017_3803.html (accessed on 10 November 2021).

43. Zhang, Y. Comprehensive Evaluation of the Location of Logistics Center Based on Entropy Method. Product. Res. 2008, 10, 108-110. [CrossRef]

44. Bai, X.M. Based on Entropy TOPSIS Agricultural logistics Center Location Model. J. Anhui Agric. Sci. 2011, 39, 11828-11829. [CrossRef]

45. Zhu, X.N.; Xi, J.Y. Study on Location of Intercity Railway Passenger Station Based on Entropy Weighting-TOPSIS. Railw. Transp. Econ. 2013, 10, 32-36. [CrossRef]

46. Zheng, S.Y.; Feng, Q.; Zheng, Z.W. Entropy Method of Location Selection of Commercial Banks. Study Pract. 2017, 75-81. [CrossRef]

47. Zha, G.F. Research on Factors Affecting Microsite Selection of Shanghai Boutique Hotels. Master's Thesis, Shanghai Normal University, Shanghai, China, 2017.

48. Li, Z.L.; Xie, N.S. Research on the Factors Influencing the Micro-site Selection of Economic Hotels-A Case Study of Changsha City Center. Mod. Bus. Trade Ind. 2019, 40, 194-196. [CrossRef]

49. Zhou, Y. Research on the Spatial Coupling of Commercial Formats and Rail Transit Stations Based on POI Data-Taking Hangzhou City as an example. In Proceedings of the Vigorous City and Countryside, Beautiful Human Settlements: Annual National Planning Conference 2019, Chongqing, China, 19 October 2019; pp. 1090-1097.

50. Jiang, M.M. Joint Office Operation and Management Model and Its Case Study. Enterp. Reform Manag. 2019, 13-18. [CrossRef] 
51. Enström, R.; Netzell, O. Can Space Syntax Help Us in Understanding the Intraurban Office Rent Pattern? Accessibility and Rents in Downtown Stockholm. J. Real Estate Financ. Econ. 2008, 36, 289-305. [CrossRef]

52. Liu, B.K.; Feng, C.C. Research of Impact of Urban Railway Transportation on Land Use Structure Based on GIS and Information Entropy. Urban Dev. Stud. 2009, 16, 149-155. [CrossRef]

53. Feng, C.C.; Li, W.X.; Zhao, F.F. Influence of Rail Transit on Nearby Commodity Housing Prices: A Case Study of Beijing Subway Line Five. Acta Geogr. Sin. 2011, 66, 1055-1062.

54. Zhao, H.; Yang, J.; Liu, C.P.; Wang, K. Measurement Method and Characteristics of Spatial Organization for Jobs-housing Misbalance: A Case Study of the Effects of Metro Systems on Jobs-housing Misbalance in Beijing. Prog. Geogr. 2011, 30, 198-204.

55. Zhen, M.C.; Zhang, J.Q.; Zhang, H.Y. Effect of Metro Transfer Stations on Office Space Agglomeration in Beijing. Prog. Geogr. 2014, 33, 499-507. [CrossRef]

56. Ying, L.L.; Niu, W.W. Evaluation of Resident Living Convenience in the Main Urban Area of Wuhan Based on POI Data. Territ. Nat. Resour. Study 2020, 14-17. [CrossRef]

57. Zhang, J.Q.; Guo, J. Satisfaction Evaluation of Office Activities in Beijing. Prog. Geogr. 2011, 30, 1225-1232. [CrossRef]

58. Wang, J.C. Innovation Space: Enterprise Clusters and Regional Development; Peking University Press: Beijing, China, 2001; ISBN 9787301049945.

59. Zhao, P.P.; Liu, Y.; Yang, J. Conglomerationg and Layout of Innovation Space in Hangzhou. Planners 2021, 37, 67-73. [CrossRef]

60. Zhang, J.Q.; Chen, Y.L.; Sun, Y. Spatial Analysis on Urban Internal Economic Spatial Structure Based on Rent of Office Buildings in Beijing City. Sci. Geogr. Sin. 2010, 30, 833-838. [CrossRef]

61. Alonso, W. Location and Land Use: Toward a General Theory of Land Rent; Harvard University Press: Cambridge, MA, USA, 1964; ISBN 9780674729568.

62. Song, B.; Gao, B. A Causality Test for Housing and Land Prices: 1998-2006. Mod. Econ. Sci. 2007, 29, 72-77. [CrossRef]

63. Gan, L.; Feng, C.C.; Wang, Q. Dynamic Relationship between Housing Price and Land price in Beijing: Based on Structural Equation Modeling. Geogr. Res. 2016, 35, 1831-1845. [CrossRef]

64. Xia, J.Y. An Empirical Analysis of the Relationship between Housing Prices and Land Prices Based on Time Series MethodsTaking Zhongshan City as an Example. Mod. Bus. Trade Ind. 2018, 39, 6-8. [CrossRef]

65. Zhao, K.; Liu, C.K. House Prices, Land Prices and Local Government Behavior. Stat. Res. 2018, 35, 15-27. [CrossRef] 